\title{
Diseño e implementación de una cabina automatizada para la desinfección de gotículas del virus SARS-CoV-2, controlada por un sistema incrustado.
}

\author{
Nicolás Andrés Vásquez Gómez, Mauricio Andrés Pacheco Mancilla \& Meglys Pérez Bernal \\ Programa de Ingeniería Electrónica y en Telecomunicaciones, Universidad Autónoma del Caribe, Barranquilla, \\ Colombia. \\ nicolas.vasquez@uac.edu.co, mauricio.pacheco@uac.edu.co,meglys.perez@uac.edu.co
}

Recibido: Octubre 08, 2020.

Recibido en su versión corregida: Diciembre 20, 2020.

https://doi.org/10.54606/Sextante2021.v24.02

Aceptación: Marzo 17, 2021.

Cómo citar: Vásquez Gómez, N., Pacheco Mancilla, M. \& Pérez Bernal, M. (2021), Diseño e implementación de una cabina automatizada para la desinfección de gotículas el virus SARS-CoV-2, controlada por un sistema incrustado. Revista Sextante, 24, pp. $13-19,2021$.

\section{Resumen}

En este artículo se presenta una cabina automatizada para la desinfección de las gotículas que contienen el virus SARSCoV-2. Esta cuenta con múltiples sensores electrónicos, los cuales la hacen trabajar de una manera automatizada y sin intervención humana. Posee sensores de temperatura y presencia, controlados por una tarjeta de sistema incrustado; con esto se busca disminuir la curva de contagio del nuevo coronavirus (SARS-CoV-2) y que por medio de esta sea posible brindar seguridad a las personas cuando se encuentren en lugares externos a sus casas, desinfectando sus objetos personales, vestimenta y pertenencias al momento de entrar o salir de un lugar. Generando en consecuente, la oportunidad a la reapertura de los sectores económicos que progresivamente se han visto afectados por esta problemática de salud pública.

Palabras clave: Cabina Automatizada; COVID-19, SARS-CoV-2; Sistema incrustado.

\section{Design and implementation of an automatized cabin for the disinfection of droplets of the SARS-CoV-2 virus, controlled by embedded system.}

\begin{abstract}
This article presents an automated booth for the disinfection of droplets containing the SARS-CoV-2 virus. It has multiple electronic sensors, which make it work in an automated way and without human intervention. It has temperature and presence sensors, controlled by an embedded system card; this is intended to reduce the contagion curve of the new coronavirus (SARS-CoV-2), and through this, it is possible to provide security to people when they are in places outside their homes, disinfecting their objects, clothing, and belongings at the time of entering or leaving a place. Consequently, generating the opportunity to reopen the economic sectors that have been progressively affected by this public health problem.
\end{abstract}

Keywords: Automatized cabin; Embedded system; COVID-19; SARS-CoV-2. 


\section{Introducción}

El virus SARS-CoV-2 tuvo inicio en diciembre del 2019 en Wuhan, China. A partir de la fecha, este, se ha ido esparciendo alrededor del mundo y, el 11 de marzo del 2020 fue declarado pandemia. Este ha causado grandes impactos en distintos sectores, pero especialmente en el sector económico y social, provocando así, que países y grandes empresas se unan para encontrar soluciones que ayuden a combatirlo y controlarlo.

La Organización Mundial de la Salud (OMS) ha dado múltiples recomendaciones para contener y prevenir los contagios de este virus, una de estas y la más importante es el lavado de manos de forma frecuente. Es necesario mencionar que, según la Organización, este virus se transmite a través de gotículas procedentes de la nariz o boca de una persona infectada. Si una persona no está infectada, y por alguna razón toca las gotículas que contienen el virus y luego se toca los ojos, la nariz o la boca, es altamente probable que se contagie.

Es por esto por lo que se tiene el lavado de manos como medida de prevención más eficaz, ya que el jabón y los desinfectantes a base de alcohol pueden destruir el virus y así evitar que lleguen a nuestro organismo.

Por otro lado, si una persona infectada estornuda o tose, saldrán gotículas disparadas desde su organismo, las cuales pueden caer sobre objetos y superficies que rodean a esta persona, como mesas, sillas, barandas, pomos, entre otros objetos como la ropa de alguna persona que esté cerca a la infectada, llevándolas consigo sin darse cuenta.

Teniendo en cuenta esto, este virus puede ser transportado de un lugar a otro a través de la vestimenta u objetos, poniendo en riesgo a cualquier persona que se encuentre a su alrededor y tenga contacto directo o físico con ella. Según lo mencionado anteriormente y buscando una solución para combatir el COVID-19 y reducir la probabilidad de contagio en el contacto entre una persona y otra, se presenta una cabina de desinfección automatizada que se pueda implementar en cualquier entorno, ya sea familiar o empresarial, ejemplo de estos son: edificios, casas, apartamentos, entre otros.
Esta cabina sigue las recomendaciones sanitarias entregadas por las entidades de salud, donde se busca brindarle seguridad a las personas que entran a un establecimiento, casa, empresa o cualquier lugar donde esta se encuentre, ya que estará ubicada en la entrada del lugar que se frecuenta, pasando la persona a través de esta para hacer la respectiva desinfección.

Esta cabina cuenta con un sensor de temperatura, que se encarga de sensar la temperatura corporal de la persona que quiera desinfectarse y emite una alerta lumínica si la persona puede seguir o no (el acceso se le denegará si presenta una temperatura mayor a la permitida, la cual es $37.8^{\circ} \mathrm{C}$ ). Además, tiene un sensor de presencia que detecta que la persona ha ingresado a la zona de desinfección, enviando una señal al sistema de control para activar 6 nebulizadores que rocían a la persona con el líquido desinfectante.

Normalmente cuando las personas salen de sus casas a un lugar público sienten desconfianza, ya que existe la posibilidad de que cualquier individuo pueda ser portador del virus. Con esta cabina se busca minimizar la inseguridad y desconfianza que se produce al estar fuera de casa e ingresar a lugares donde concurren mucha gente. Por esto, con la implementación de la cabina automatizada de desinfección se les brinda a los individuos la seguridad de estar libres de gotículas del virus, en su vestimenta y lo demás que esté al alcance de los rociadores, en los lugares donde ésta se encuentre.

\section{Metodología propuesta}

Con miras a cumplir el objetivo de tener una cabina de desinfección autónoma, totalmente implementada y funcional, se planteó una línea de trabajo que fue puesta en marcha en una primera fase de diseño, para así proceder con el desarrollo y elaboración de la cabina, junto con su respectiva interfaz gráfica, a las cuales se les ejecutarán una serie de pruebas y evaluaciones. Esta línea de ejecución se encuentra descrita en la Figura 1.

Para la realización de esta cabina de desinfección autónoma en la fase de diseño se eligió una tarjeta Raspberry Pi ZeroW como dispositivo principal, ya que desde esta se realizará la automatización de la cabina, y se controlará la manera en cómo funcionará. 


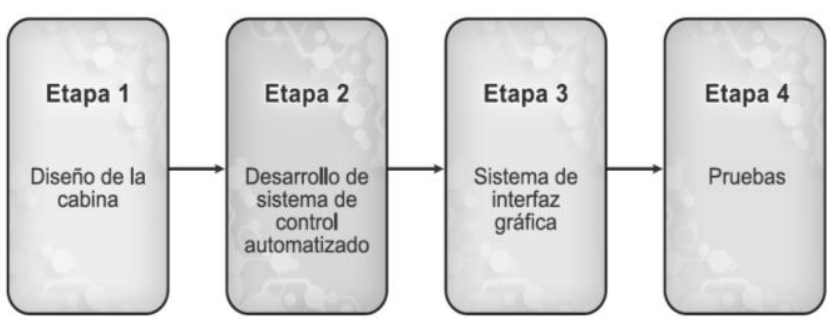

Figura 1. Diagrama de bloques de la metodología de trabajo seguida para la elaboración de la cabina de desinfección autónoma.

Fuente: Los autores.

Luego se realizará un cuadro comparativo donde se puedan evaluar los líquidos desinfectantes más eficaces e indicados para aplicación humana. Posteriormente se ejecutará un benchmarking de los sensores que sean compatibles con el sistema incrustado Raspberry Pi ZeroW, para lograr un exitoso acoplamiento y comunicación entre sensores y la placa controladora.

Después de tener toda la información y el cuadro comparativo realizado, se procederá a elegir los elementos adecuados para el proceso. Seguidamente se empezarán las labores de diseño e implementación de un sistema de desinfección mecánico, este se elaborará teniendo en cuenta las necesidades del caso. Teniendo listo el montaje de la cabina de desinfección en lo que a secciones externas y de protección de elementos internos concierne, se implementarán los sensores elegidos con el sistema incrustado (Raspberry Pi ZeroW), para así poder tener una cabina automatizada completa, tanto en sus partes mecánicas como electrónicas. (ver Figura 2)

El líquido desinfectante escogido es el NSO (Nebula Superficie Orgánica), el cual es un componente del aceite de tomillo compuesto de extracto de aceite esencial de tomillo y citrato de sodio. Cabe resaltar que es una mezcla natural de compuestos a partir de aceites esenciales naturales. Por otro lado, es un producto Biocida, Bactericida, Fungicida y Viricida de amplio espectro. Este producto se comparó con otros compuestos disponibles en el mercado, los cuales también se utilizan para desinfección de superficies, y se concluyó que es el más indicado ya que no es nocivo para la salud, no irrita la piel, no tiene olor fuerte y es a base de aceites naturales.

\section{Impacto esperado}

Con el diseño y elaboración de esta cabina automatizada de desinfección se espera un impacto social, personal y económico. Al disminuir la curva de contagio del coronavirus (SARS-CoV-2) se pueden conseguir beneficios en el área económica, dado que se podrían reactivar sectores afectados por el aislamiento obligatorio que se ha tenido en los últimos meses y que se tiene en la actualidad en algunas ciudades, ya que cada persona tendrá seguridad al saber que el establecimiento donde desea ingresar posee un sistema automatizado que puede desinfectar sus objetos, ropa y pertenencias, ya sea al momento de entrar o al momento de salir.

Se sabe que el método de contagio más común es por contacto, es decir, tocar superficies que tengan partículas de SARS-CoV-2 y luego llevarse las manos a la cara. Esto puede ocurrir en lugares que son indispensables para el sustento de la sociedad como son los supermercados, donde las personas siempre están teniendo contacto con los productos que van a comprar. Por tal motivo, al utilizar esta cabina de desinfección se les otorga a los compradores un alto porcentaje de seguridad y confianza en cuanto al bajo nivel de carga viral presente en el recinto, debido a que al momento del ingreso al lugar a cada persona se le haría la respectiva desinfección, tanto de su vestimenta como de sus pertenencias, haciendo así que todo el lugar se encuentre en una alta probabilidad de estar libre de partículas de SARS-CoV-2. Es necesario resaltar que las personas deben seguir con el uso del tapabocas para que estas cabinas tengan un buen resultado.

A partir de esto, habrá lugares donde la propagación del Covid-19 será casi nula ya que, todas las personas que se encuentren en el lugar específico estarán desinfectadas, al igual que sus pertenencias. Dado que si bien, en la actualidad al momento de ingresar a un lugar solo se le toma la temperatura y en algunos casos se les desinfectan las manos, pero no pasan por ningún proceso de desinfección total.

\section{Usuarios directos e indirectos}

El desarrollo y creación de este sistema automatizado está orientado en el análisis de los 


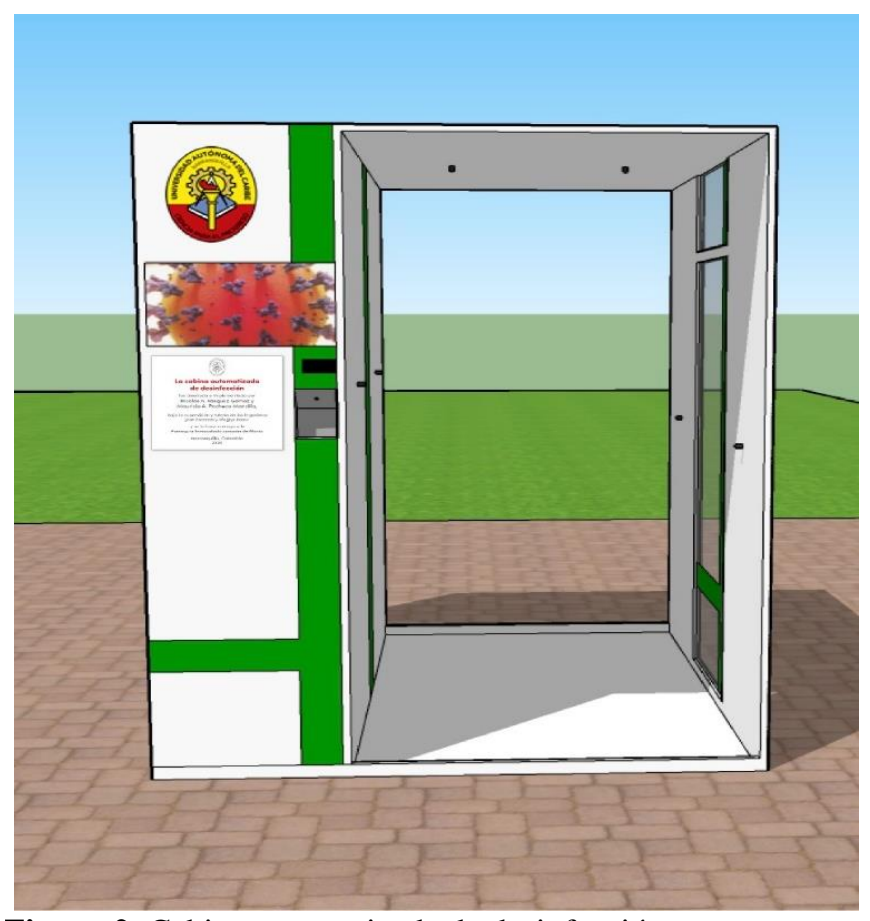

Figura 2. Cabina automatizada de desinfección.

Fuente: Los autores.

usuarios directos, siendo estos los residentes de la ciudad de Barranquilla y su Área Metropolitana. Esta gran zona del departamento del Atlántico, al momento de realizar el estudio, se encontraba en alerta naranja por la alta cantidad de casos tanto históricos y activos (6.691 y 4.934 respectivamente), como el número de muertes que llevaba hasta el momento (297). Por otra parte, como usuarios indirectos tenemos a las empresas, centros comerciales y/o comercios que puedan utilizar esta cabina, ya que le brindarían una mayor seguridad a la hora de ingresar públicos a sus recintos.

\section{Diseño e implementación}

Para el diseño e implementación se tuvieron en cuenta costos, materiales e insumos necesarios para la elaboración de una cabina junto a una pequeña bodega donde se albergarían los equipos electrónicos, cableado y el líquido desinfectante.

Se diseñó la cabina en el programa SketchUp (ver: Figuras $\underline{2}, \underline{3}$ y $\underline{4}$.)

\section{Materiales:}

Tubos de aluminio.

Remaches.

Tornillos.

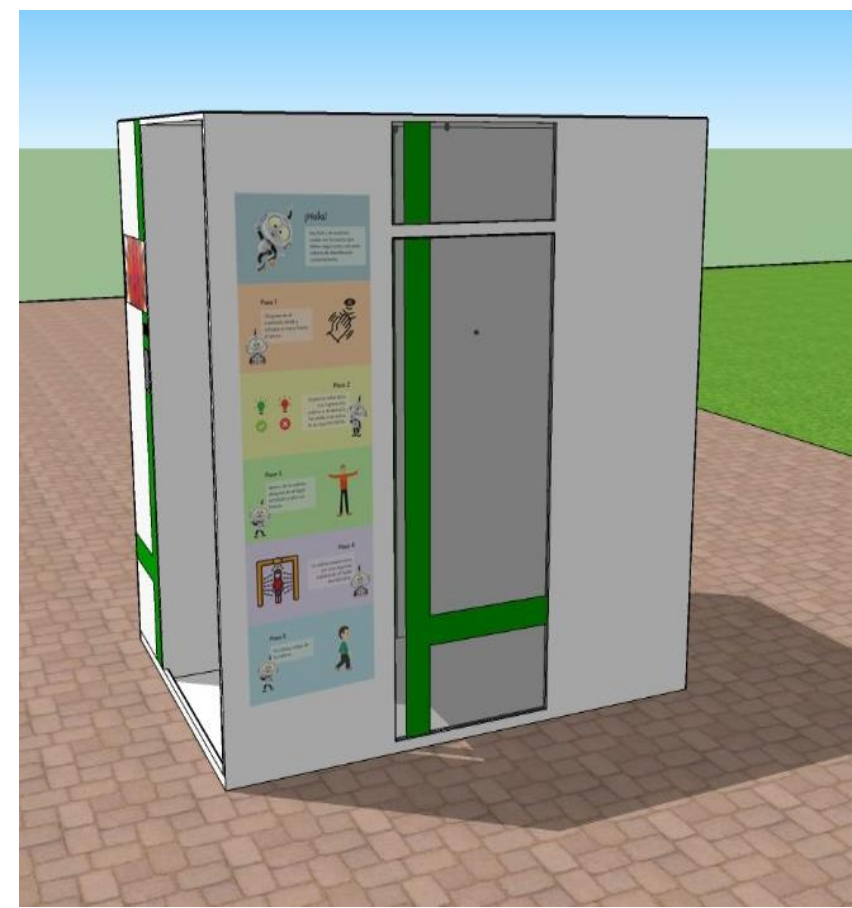

Figura 3. Cabina automatizada de desinfección.

Fuente: Los autores.

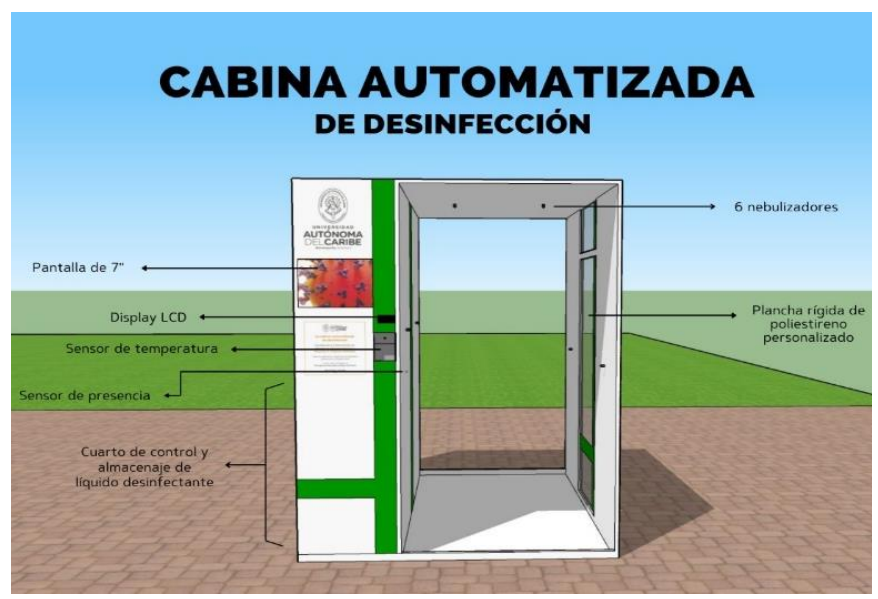

Figura 4. Cabina automatizada de desinfección.

Fuente: Los autores.

Nebulizadores.

Canaletas.

Motobomba.

Mangueras.

PVC.

Tablet de 7".

Display LCD.

Cargador de 12v.

Producto desinfectante NSO.

Raspberry Pi Zero W.

Sensor de Presencia.

Sensor de Temperatura.

Luz led de color verde.

Luz led de color rojo.

Relé.

Cables de conexión. 
Caja Láminas de Zinc.

Componentes varios para elaborar circuitos.

Caracterización de la cabina de desinfección automatizada.

Es una cabina, (ver Figura 4) que tiene un tanque de almacenamiento de líquido desinfectante de hasta 30 litros. Con base a las pruebas realizadas se obtuvo que, por cada litro de líquido desinfectante la cabina puede ser utilizada por 56 personas, esto quiere decir que si se utilizan 20 litros de NSO (líquido desinfectante usado) la cabina puede ser usada por 1120 personas, y si se utilizan 30 litros (capacidad máxima del tanque de almacenamiento) tendría capacidad para desinfectar aproximadamente a 1680 personas.

\section{Funcionamiento}

Para su óptimo funcionamiento, la cabina (ver Figura 4.) es controlada por el sistema incrustado Raspberry PiZeroW, el cual tiene un código desarrollado en el lenguaje Python, y su plataforma de desarrollo es el sistema operativo Raspberry Pi OS, siendo este una distribución del sistema operativo GNU/Linux, basado en Debian.r. El código consiste en censar la temperatura y presencia para determinar si una persona puede ingresar o no a la cabina. Dependiendo de estas variables, se encenderán testigos lumínicos y la motobomba, para que expulse el líquido desinfectante a través de los 6 nebulizadores, y así desinfectar a la persona que se encuentre dentro. Con esta premisa se procede a explicar mejor el funcionamiento de la cabina con el diagrama de flujo de la Figura 5.

El primer paso para el correcto uso de la cabina es acercarse al sensor de temperatura corporal para que este tome la temperatura de la persona. Cuando el sensor capta un dato, este se envía a la Raspberry Pi para su procesamiento. Se computa con el valor umbral que se estableció en el código y toma una decisión. Si su temperatura es menor a $37.8^{\circ} \mathrm{C}$ se activará un testigo lumínico de color verde, indicando que puede usar la cabina. En el caso de que la persona presente una temperatura igual o mayor a $37.9^{\circ}$ se activará un testigo lumínico de color rojo, indicando que no puede usar la cabina.

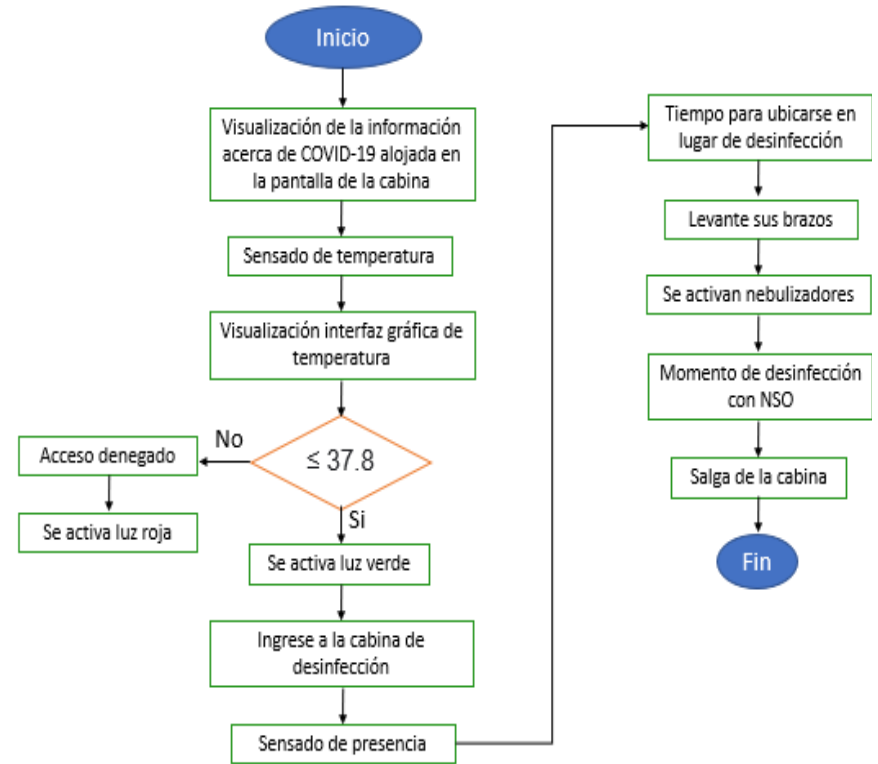

Figura 5. Diagrama de flujo del funcionamiento de la cabina en cuanto a la toma de decisiones.

Fuente: Los autores.

Al terminar esa etapa el usuario ingresa a la cabina, y en ese instante un sensor de movimiento detecta la presencia de un objeto. La cabina le da un tiempo prudente a la persona para que se ubique, y posteriormente se active el sistema de nebulización, el cual desinfectará al usuario con el líquido NSO. Como paso final la persona se retira de la cabina.

\section{Conclusiones y trabajos futuros.}

A partir del diseño y elaboración de este sistema se puede concluir que, en la actualidad el Covid-19 ha causado grandes impactos en distintos sectores, específicamente en el sector económico y social, donde países y empresas se encuentran buscando formas para mitigar esta emergencia sanitaria. Es por ello por lo que se propone la idea de lograr una disminución en los casos y decesos a través de la creación e implementación de una cabina de desinfección automatizada. Con esto se puede confirmar la forma como se logra implementar la ingeniería en cualquier problema que se presente en la sociedad actual.

En este caso se pudo implementar una cabina automatizada para la desinfección de las partículas que contienen el virus SARS-CoV-2 de una manera innovadora, contiene un sensor de temperatura y de presencia que hacen que la experiencia de la cabina sea diferente a una convencional.

Facilita al usuario saber si cumple con las condiciones para entrar al establecimiento o no. Por 
ejemplo: el tener temperatura normal indica que puede continuar con el proceso, puesto que la cabina muestra una luz roja si la persona tiene la temperatura alta.

Esto es una solución para la problemática que tenemos hoy en día, por lo que, en cualquier lugar que se implemente, sea en espacios residenciales o empresariales, se brinda tranquilidad al usuario, debido a la desinfección que ofrece la misma.

Por último, se considera que el alcance que tiene este proyecto es bastante alto, ya que el virus se encuentra entre nosotros y hoy en día las formas de cuidarnos es llevando el tapabocas, lavarnos las manos, utilizar alcohol y mantener el distanciamiento social, es decir, estar en constante desinfección. Es por esto por lo que una cabina que desinfecte a los individuos al momento de entrar a un lugar en el que se va a estar por largo o corto tiempo es una excelente forma de evitar los contagios por contacto. No obstante, cabe recordar que no se puede dejar a un lado el uso continuo de las demás medidas de bioseguridad para tener mayor protección.

\section{Recomendaciones para los trabajos futuros.}

Habiendo notado el amplio uso que tiene la tarjeta de hardware libre Raspberry Pi Zero W y los usos que se le puede dar en la aplicación de la cabina de desinfección, se dejan por sentadas algunas recomendaciones en cuanto a avances que se le pueden agregar a la cabina en un futuro. Esto es: utilizar un sensor de nivel, controlado por la misma Raspberry Pi Zero W, que indique cuando el líquido desinfectante, almacenado en la bodega de la cabina, se esté acabando y esto se manifieste en la pantalla o con una luz de alerta.

Por otro lado, se recomienda utilizar un servidor en el cual se guarden todos los datos de temperatura de los usuarios que utilizan el sistema, para así, tener registrada la información de cuantas personas utilizan la cabina diariamente. En adición a lo anterior, se puede utilizar o agregar un servidor donde ya exista una base de datos, en la cual estén guardadas el número de cédula de los empleados de una empresa en específico y por medio de una pantalla táctil las personas puedan ingresar su cedula y se guarden sus datos de temperatura y cuantas veces utiliza la cabina.
Por último y no menos importante, también se recomienda ampliar la capacidad del tanque de almacenamiento dependiendo de cuantas personas vayan a utilizar la cabina. Para esto se debe tener en cuenta que si se aumenta el tanque de almacenamiento ocasionará la necesidad de aumentar las dimensiones de la bodega que posee la cabina en su sección lateral.

\section{Referencias}

Ayala, J. Zapata, $S$ (2016). Diseño de Automatización para una cabina de Seguridad Biológica.

https://repositorio.itm.edu.co/bitstream/handle/ 20.500.12622/2097/Rep_Itm_pre_Zapata.pdf?s equence $=1 \&$ is Allowed $=y$

Amaya, G. (2020, junio 16). Atlántico supera los 10.000 casos de coronavirus. El Heraldo. https://www.elheraldo.co/colombia/atlanticosupera-los-10000-casos-de-coronavirus-734720

Alcaldía Distrital de Barranquilla. (2020). Alcalde Jaime Pumarejo declara alerta naranja en Barranquilla por coronavirus y centraliza en el CRUE del Distrito los usos y disponibilidades hospitalarias.

https://www.barranquilla.gov.co/salud/alcaldepumarejo-declara-alerta-naranja-barranquillacoronavirus

BBC Mundo (2020, marzo 2020). Coronavirus: cómo te puedes contagiar y cómo no. https://www.bbc.com/mundo/noticias51982673\#: :text=\%22Las\%20manos\%20est\% C3\%A1n\%20todo\%20el,de\%20la\%20Salud\%2 C\%20Jarbas\%20Barbosa

León, J., Abad, E., (2020). Desinfectantes y antisépticos frente al coronavirus: Sintesis de evidencias y recomendaciones. Enfermería Clínica.

https://dx.doi.org/10.1016\%2Fj.enfcli.2020.05.0 $\underline{13}$

Liu, J., Liao, X., Qian, S., Yuan, J., Wang, F., Liu, Y., Wang, Z., Wang, F., Liu, L., Zhang, Z., (2020). Community Transmission of Severe Acute Respiratory Syndrome Coronavirus 2, Shenzhen, China, 2020. Emerging Infectious Diseases, 26(6). 
https://wwwnc.cdc.gov/eid/article/26/6/20-

0239_article

Morguerza, J., Perelló, S., Martín, I., Aceña, V., Cuesta, M., Lancho, C., González, C., (2020). Suficiencia sanitaria y Covid-19. Methaodos, $8(1)$, 140-168. https://www.methaodos.org/revistamethaodos/index.php/methaodos/article/view/34 $\underline{9}$

Organización Mundial de la Salud [OMS]. Coronavirus. https://www.who.int/es/healthtopics/coronavirus\#tab=tab_1

Penalver, A. (2020). Desactivación de actividad viral de Covid-19 por radiación UV-C lejana. https://vanilla.coronavirusmakers.org/uploads/e ditor/zh/23obwl0e20rd.pdf

Palacios, et al. (2021). COVID-19, una emergencia de salud pública mundial. Revista Clínica Española, 221(1), 55-61.

Valls, J., Tobías, A., Satorra, P., y Tebé, C. (2021). COVID19-Tracker: una aplicación Shiny para analizar datos de la epidemia de SARS-CoV-2 en España. Gaceta sanitaria, 35(1), 99-101. https://doi.org/10.1016/j.gaceta.2020.04.002

Clínica Barcelona, 2020. ¿Qué es el Coronavirus SARS-CoV-2?

https://www.clinicbarcelona.org/asistencialenfe rmedades/covid-19/definicion

(Organización Mundial de la Salud, 2020). Preguntas y respuestas sobre la enfermedad por coronavirus (COVID-19)

https://www.who.int/es/emergencies/diseases/no vel-coronavirus-2019/advice-for-public/q-a-

coronaviruses\#: : text $=$ Lo $\% 20 \mathrm{~m} \% \mathrm{C} 3 \% \mathrm{~A} 1 \mathrm{~s} \% 20$ importante\%20que\%20hay, en\%20superficies \% 20de\%20cart\%C3\%B3n

Julián Pérez Porto y María Merino, 2017. Definición de automatización https://definicion.delautomatizacion/

Julián Pérez Porto y Ana Gardey, 2010. Definición de sensor.

https://definicion.de/sensor/ 